\title{
Third Sector and Social Media
}

\author{
Ryan Deschamps \& Kathleen McNutt \\ University of Regina
}

\begin{abstract}
While social media has become a mainstay of communication in the twenty-first century, many organizations still struggle to include it in their operations. This is no less the case for organizations in the third sector. However, evidence-based practices tying social media activity to social media success are still elusive in the field. Examining the Facebook and Twitter presence of 45 Canadian organizations concerned with education, disaster relief, and environmental advocacy, the authors evaluate social media practices used by third sector organizations. Borrowing from Mark Granovetter's (1973) work on the strength of social ties, the authors found that disaster relief organizations tended toward activities to build emotionally intense, or "strong," relationships, while educational organizations offered more informational means to build "weak" relationships based on common interests. Environmental organizations used both strategies, but were less likely to broaden their activities beyond Facebook and Twitter. The authors propose identifying organizations' weak-tie/strong-tie strategies as a tool for evaluating social media activity in the not-for-profit sector. They argue that co-ordinating both types of strategies is necessary for successful social media campaigns.
\end{abstract}

\section{RÉSUMÉ}

Bien que les médias sociaux soient devenus omniprésents dans la communication au $21^{\text {ème }}$ siècle, plusieurs organisations tardent à les inclure dans leurs opérations. Ceci n'est pas moins le cas des organismes du troisième secteur. En même temps, la recherche établissant un rapport entre le recours aux médias sociaux et le succès d'une organisation demeure peu concluante. Dans cet article, les auteurs évaluent l'utilisation de médias sociaux par des organisations du troisième secteur en examinant la présence sur Facebook et Twitter de quarante-cinq organismes canadiens se spécialisant en éducation, en secours aux sinistrés et en activisme écologique. En recourant à l'œuvre de Mark Granovetter sur la puissance des liens sociaux, les auteurs ont trouvé que les organismes de secours aux sinistrés tendaient à effectuer des activités axées sur des relations intenses d'un point de vue émotionnel, donc "fortes ", tandis que les organismes éducationnels avaient une 


\section{Deschamps \& McNutt (2014)}

approche plus informationnelle afin de construire des relations "faibles " fondées sur des intérêts communs. Les organisations environnementales quant à elles employaient les deux stratégies, mais elles étaient moins enclines à élargir leurs activités au-delà de Facebook et Twitter. Les auteurs proposent d'identifier les stratégies d'attaches faibles et fortes comme outils pour évaluer le recours aux médias sociaux dans le secteur sans but lucratif. Ils soutiennent que la coordination des deux types de stratégie est nécessaire pour réussir les campagnes de médias sociaux.

Keywords / Mots clés : Social media; Communications; Social networking; Strategies; Best practices / Médias sociaux; Communications; Réseautage social; Stratégies; Pratiques d'excellence

\section{INTRODUCTION}

Social media is changing how the third sector serves clients and engages donors, volunteers, and staff. The social media marketplace is vast and offers numerous digital tools (Kaplan \& Haenlein, 2009; Waters \& Jamal, 2011). From an organizational perspective, social media can increase community presence, maximize impacts, and improve effectiveness and efficiency (Curtis et al., 2010; Miller, 2009). From a social perspective, social media can foster social inclusion and encourage stakeholder participation (Vance et al., 2009). The growth of social media trends, combined with potential for relationship development through social networking, suggests that third sector organizations will increasingly rely on digital technologies if they wish to succeed in a society characterized by constant Internet use. This will require both social media expertise and creative experimentation.

While many nonprofits were early adopters of social media tools (Briones et al., 2011; Purdy, 2011), not all nonprofits are leveraging digital technologies. Social media expertise is a major barrier to doing so, and while many nonprofits are aware of the potential offered by social collaboration technologies, they often lack an understanding of social media optimization (Waters et al., 2009). This lack of social media fluency is compounded by an inadequate staffing capacity, inadequate training, and Internet inaccessibility. Nevertheless, there is a strong consensus that nonprofits must actively engage the general public, community members, and clients using Web 2.0 platforms (Kanter \& Fine, 2010; Neff \& Moss, 2011).

Utilizing the power of social media means more than simply creating a Facebook page or uploading content onto YouTube. In the last five years, interest in Web 2.0 technologies in the public and not-for-profit sectors has produced a flurry of advice on how to maximize impact and increase engagement (Grant, 2009; Shirky, 2011). As nonprofits shift their activities away from the "broadcast paradigm," associated with Web 1.0, toward the "dialogical paradigm" associated with Web 2.0 (Greenberg \& MacAulay, 2009), it will be crucial to develop evidence-informed performance measures for assessing the impact of social media activities on social inclusion. Recent work exploring online advocacy has proposed that online engagement occurs in stages, beginning with basic information sharing, establishing trust relationships, and then using those established connections to call for advocacy action (Guo \& Saxton, 2014; Lovejoy \& Saxton, 2012). However, staged approaches to online engagement tend to be heuristics unable to explain human motivation and group dynamics; in other words, these might help explain participatory processes, but they do not provide benchmarks for performance, nor do 


\section{Deschamps \& McNutt (2014)}

they supply the types of administrative advice required to achieve an organization's communication objectives (Fischer, 2003; Sabatier, 1991). In the future, measures of efficiency, effectiveness, and accountability will all be major drivers behind the optimization of social media activities (Curtis et al., 2010), while relationship strategies will determine organizational impact and reach.

Unfortunately, scholars and practitioners have only recently become actively engaged in rigorous examinations of social media applications and the capacity of digital tools to serve organizational missions and programming goals (Banias \& Malita, 2011; Waters, 2009). Currently, the lack of standardized smart practices creates challenges for nonprofits, especially in selecting the appropriate social media tool for the intended purpose (Watling, 2011). While numerous commentators offer advice on how to optimize third sector social media outcomes, a majority consensus has yet to emerge.

The trouble stems from the fact that social media technologies are currently outpacing research efforts, due to their novelty and rapid spread throughout society. In addition, members of not-for-profit organizations who are online content creators do not necessarily see eye-to-eye with their co-workers about the role of social media in engaging clients (Kenix, 2008). Still, nascent literature offers evidence-informed strategies for employing social media tools in nonprofits for the purposes of 1) serving clients, 2) eliciting volunteers and donations, 3) engaging civil society, and 4) improving accountability and transparency. While there is still a great deal of experimentation occurring across these four dimensions of nonprofit social media applications, these strategies will assist nonprofits in planning, implementing, and monitoring their social media activity, while providing some base-line performance measures.

The research presented in this article uses evidence-informed analysis to evaluate the social media practices of different types of nonprofits: those concerned with education, environment, and disaster relief. While categories such as these are often self-selected by the organizations, we consider education organizations to be those that promote some kind of learning, or discipline (e.g., Historica-Dominion Society's promotion of Canadian history). Our education category does not include quasi-governmental organizations such as universities and schools. Environmental organizations raise social awareness of environmental issues such as biodiversity, climate change, and food security. The range of issues run the gamut, from specific environmental curriculum services through the SEEDS Foundation, to broader environmental awareness from groups such as Sierra Club Canada. Disaster relief organizations provide human welfare support during and after a disaster as well as support for rebuilding infrastructure. These groups range from Canadian chapters of very large multi-national organizations, such as the Red Cross, to smaller national organizations, such as the Bosnian-Canadian Relief Fund.

Our project begins with a brief literature review on emergent smart practices in nonprofits' application of social media tools, drawing advice from both scholars and practitioners. Next, we discuss Granovetter's (1973) strength of weak ties thesis, and suggest that tie strength strategies are a critical aspect of optimizing social media outcomes. In the next section, we examine a number of key social media indicators to evaluate the extent to which nonprofits concerned with disaster relief, education, and the environment are applying smart practices and developing tie strength strategies. Finally, we conclude with some key recommendations that will help nonprofits move toward their social media programming goals. 


\section{Deschamps \& McNutt (2014)}

\section{EMERGENT SMART PRACTICES}

Social media optimization is a process of online reputation management, wherein organizations seek to maximize the impact of their social media activities by increasing linkability, by incorporating features that assist in message dissemination (RSS feeds, sharing buttons, and so forth), and through promotional activities that attract attention to the organization's goals (social networking sites, YouTube) (Frick, 2010; Lovett, 2011). The main goal of social media optimization is to improve an organization's web presence; however, we currently know little about the macro-level online impact Canadian of nonprofits. Unlike for-profit organizations that use social media to gain market advantage, nonprofits' "financial outcomes are merely a means to an end. The ultimate strategic goal is the fulfillment of some social mission-that is, the creation of public value" (Hackler \& Saxton, 2007, p. 477). Thus, the uses and applications of social media in the third sector encompass a number of strategies for cultivating relationships with the public. To date, social networking sites (SNS) are the most popular social media tools for this purpose, since the sites allow an organization to share their mission, invite members to events, actively communicate with members, share information, post calls for volunteers, and undertake targeted fundraising activities.

Extensive evidence suggests that social media is changing advocacy and how civil society organizes for action. There are numerous examples of social media mobilizing people around a specific cause; however, the tactics employed to achieve these outcomes are varied and are often beyond the control of any one organization. There are several fundamental differences between traditional civil society and virtual civil society. First, there has been the emergence of "flash activists," who use social media to mobilize the masses and promote issue awareness using an arsenal of social media tools, including Twitter, blogs, and Facebook (Mehta, 2011). Second, social media has radically increased the influence of free-agent activists not connected to organizations but rather to causes. Third, social media offers systems for the evaluation of content ("likes," for instance) that can "power-charge" some communications while potentially downplaying others (Scott \& Orlikowski , 2012). By bringing their organizational brand to social media channels, nonprofits face a conundrum: they may increase influence overall, but decrease their control of their message.

The implications of this trend for nonprofits are threefold. First, nonprofits must go beyond marketing their organization and focus on marketing different causes connected to their mission. Second, nonprofits using social media must treat the technology as participatory, enabling people to create as well as consume media (Lai \& Turban, 2008; Russo et al., 2008). Third, nonprofits must build trust (Reynolds, 2010). Nonprofits have numerous opportunities to tap into different virtual grassroots groups and online social movements by joining networks advancing or supporting causes that fall within the mandate of the organization. In the Web 2.0 era, listening is as important as talking. Tapping into collective intelligence and learning what people are saying and doing provides nonprofits with crucial resources for co-ordinating events, designing programs, and garnering support. It also ensures continuous learning among their staff, as new technology and online social activities shift the social media landscape. However, it should also be noted that many smaller nonprofits may find it difficult to maintain virtual relationships due to a lack of human resource capacity and/or social media fluency. 


\section{Deschamps \& McNutt (2014)}

To a nonprofit, accountability is critical, as nonprofit organizations must be trusted to be successful. Gordon, Khumawala, Kraut, and Neely (2010) define accountability as "both a legal and ethical obligation for nonprofit organizations that purport to use resources received to further their charitable mission" (p. 209). As an ethical obligation, accountability includes a number of different reporting activities that justify how resources are managed; it is also a legal obligation, as nonprofits often have reporting requirements through government funding programs. Websites are key to the third sector's accountability efforts, making available annual reports, financial statements, and organizational missions. These public disclosure practices correlate with improved levels of trust, increased charitable giving, and greater volunteerism (Dhebar \& Stokes, 2008; Gandía, 2011). Mission statements are key, because organizations "lacking a profit motive rely on a mission statement to articulate their raison d'être" (Kirk \& Nolan, 2010, p. 474). Financial reporting, whether in the form of an annual report or financial statement, further demonstrates accountability to funders (Waters, 2007). Internet sharing of programming can also support the spiritual need of volunteers to know that they are helping a worthy cause (Amichai-Hamburger, 2008).

Scholarly work suggests nonprofits may improve accountability along two dimensions:

a) disclosure, which concerns the transparent provision of key information on organizational finances and performance, and

b) dialogue, which encompasses the solicitation of input from and interactive engagement with core stakeholders. (Saxton \& Guo, 2011, p. 271)

According to Berman, Abraham, Battino, Shipnuck, and Neus (2007), full disclosure on social networking sites means providing a detailed description of an nonprofit's mandate and history, identification of those individuals maintaining the site, visual cues that identify the organization, and links back to their website. Developing online relationships with users can, however, be problematic for some professional groups, in particular those such as medical professionals whose relationships require some level of confidentiality or professional distance (Mansfield et al., 2011).

Despite existing social media best practices, in some instances nonprofits might adopt all of these principles and still not optimize their social media impact. Take, for example, the outcomes for the two nonprofits that won the Hugh Jackman Twitter contest. In April 2009, Australian actor Hugh Jackman pledged to donate AUS $\$ 100,000$ to the charity that could convince him in 140 characters or less of why their cause was most deserving of the donation. As one of the first philanthropic exercises on Twitter, the contest received a great deal of attention in both social and mainstream media and is an oft-cited example of how social media is changing the charitable landscape. In the end, Jackman split the money between two American charities: Operation of Hope and charity: water. Operation of Hope was founded by Dr. Joseph Clawson, an ears, nose, and throat doctor; it is an organization of charitable doctors who perform facial reconstructive surgeries. The organization had received mainstream media attention as a feature in $O$ magazine prior to the Jackman-inspired contest; following the contest, CNN also began reporting on the organization's work. charity: water, founded in 2006 by Scott Harrison, is a development organization that provides clean and safe drinking water to people in over 20 developing nations. 


\section{Deschamps \& McNutt (2014)}

Both organizations exercise the best practices discussed above - providing financial statements, using multiple social networking sites, eliciting donations and volunteers, and so forth. Yet when we compare the two organizations' charitable contributions and social media audience, Operation of Hope and charity: water experienced very different social media outcomes following the contest. Operation of Hope had approximately 1,318 Twitter followers and 1,179 likes on Facebook while charity: water had approximately 1.42 million followers on Twitter, and 294,000 likes on Facebook. In terms of donations, Operation of Hope's total contributions in the $2008 / 2009$ tax year were $\$ 360,752$, dropping in 2010/11 to $\$ 207,306$. In contrast, charity: water received \$5,498,293 in contributions in 2008, and \$24,950,437 in 2011.

What explains these differences? Leadership style? Design? The cause? In the next section, we explore the possibility that the nature of nonprofits' relationships with their communities, the public, and organizations with similar interests is a strong predictor of social media success. We explore how the strength of ties thesis might be strategically applied to optimize nonprofit's social media outcomes. We further hypothesize that tie strength strategies are most effective when other social media smart practices are already implemented.

\section{THE IMPORTANCE OF TIES}

Mark Granovetter's (1973) strength of weak ties thesis suggests that every person will have both acquaintances and friends. Acquaintances are weak ties, individuals with whom social contact is infrequent and often context specific. Friends are strong ties, members of one's egocentric clique; and the more similar the individuals, the stronger the ties (Granovetter, 1973, p. 1362). In social networks characterized by homophily (the "birds of a feather" effect), strong ties are very dense, with few opportunities to make new connections; networks with numerous bridging opportunities (explained below) are characterized by multiple weak ties and loosely knit relationships. In the nonprofit field, actors lacking policy acquaintances, or weak ties, will lack opportunities to access new ideas and information, impairing the innovation process. As Granovetter (1983) explains, "The macroscopic side of this communication argument is that social systems lacking in weak ties will be fragmented and incoherent. New ideas will spread slowly, scientific endeavors will be handicapped" (p. 202). The process of connecting to new acquaintances and developing friendships may be expedited by bridging other actor's networks (Granovetter, 2005).

Bridging refers to a process by which one actor or organization connects to another actor or organization, providing a link between the two networks and expanding the opportunity to diffuse information or connect to new actors individuals. Based on Ronald Burt's (1992) structural holes theory, network innovation is the product of brokering opportunities across gaps in social structure, or structural holes. Networked actors who engage in locating ideas, diffusing information, and brokering exchange enjoy a higher status in that they have privileged access to network resources. The production of ideas and the establishment of new relationships are thus accelerated through the multiplication of weak ties, particularly ties that bridge holes in the social structure (Burt, 2004). 


\section{Deschamps \& McNutt (2014)}

Though weak ties are important, these linkages may lack diversity in terms of interaction and information sharing. Thus, for nonprofits, the development of strong ties will also be a priority. Haythornathwaite (2002) suggests that strong ties are evident in long-established, emotionally intense and reciprocal arrangements. These arrangements can be formal, such as a contract arrangement, or informal, as in a sharing of values. Studies of web-based networks have tended to assume that online social ties behave similarly to offline social ties (McNutt, 2012). In reality, this assumption only means that stronger ties will have different characteristics from weaker ties. Reciprocation is one example of how strong ties can be observed on social media sites. For instance, an organization that receives more comments on its social media sites can be said to have stronger user ties than one that receives fewer. Thus, actions on social media that attempt to build reciprocal relationships with users can be said to apply a strong-tie strategy.

\section{CASE SELECTION AND ANALYSIS}

To examine the importance of social ties to not-for-profit organizations' social media performance, we examined the social media activities of 45 organizations from the Canadian Revenue Agency (CRA) Charitable Funding databases. Fifteen of the organizations were selected from the "Education" category, fifteen were selected from "Disaster relief," and fifteen were environmental organizations selected from "Benefits to the community and other" category. All three categories are CRA classifications of charities and foundations in Canada. Previous studies of social media use in the nonprofit sector have shown that variables like organization size, lobbying activities, and fundraising budget either do not correlate or negatively correlate to social media use (Nah \& Saxton, 2013). However, donor dependence has shown some correlation to frequency of social media use, so our sample contains organizations that issued more than ninety thousand dollars in charitable tax receipts in 2012, as recorded in line 4500 of their T3010 Registered Charity Information Return. We also confirmed that the organizations had some form of social media presence promoted on their website. Because we wanted to examine social media smart practices, and not institutional strength, we excluded quasi-government institutions, such as universities and both public and private schools, from the sample. What resulted was a purposive sample of between 40 and 100 organizations in each category, from which a random sample of 15 organizations was extracted. The sizes of the organizations run from small to mid-sized, such as Canadian Aid for Chernobyl, to very large multi-national organizations, such as the Sierra Club and the Red Cross. For each organization, we conducted a search for their website, Facebook page, and Twitter account and observed the ways in which each organization approached their social media presence. In particular, we analyzed how organizations attempted to develop connections with existing users and how the organizations approached soliciting (Facebook) "likes" and/or (Twitter) "follows" from new users in order to increase their overall presence.

To complement our observations about each organization, we developed 21 qualitative measures to assess that social media sites are being used, how they are being used, and what evaluative markers might indicate success on social media sites. The purpose of these measures was to assess the manner in which each organization attempted to position itself strategically toward Internet users. Unlike profit-based companies, not-for-profits usually orient their positioning strategy to a social purpose, instead of to a particular product or service (Chew \& Osborne, 2009). Past content analysis of not-for-profit activity has focused primarily on social media activity, such as one-way communication ("information"), two-way conversations ("community"), and requests ("actions") (Lovejoy \& Saxton, 


\section{Deschamps \& McNutt (2014)}

2012). Our method applies a more interpretive approach. For instance, using "one-way" communication to recognize donors and volunteers not only expresses appreciation for those who work for the organization, but also asserts the value of the cause in the eyes of the community. It is quite different from the "one-way" sharing of a statistic about some particular social need. We have therefore avoided these categories, instead choosing to measure organizations' strategies for "bridging" and "bonding," applying these to the diversity of their social media uses, and measuring them against four benchmarks for evaluation purposes.

After initial pretesting, we classified six criteria as bonding social media strategies based on activities that seek to strengthen existing relationships and strengthen the organization's reputation. These include: 1) recognizing volunteers and staff, 2) recognizing donors, 3) responding directly to user comments, 4) highlighting offline activities, 5) mentioning partner or related organizations, and 6) using the "Causes" app to raise donor funds for the organization. In general, these strategies either help build relationships with people already engaged with the organization, or facilitate a level of reciprocation from the organization's users to build community ties online. Maintaining these close ties allows the organization to rely on its community to spread the word beyond the walls of the organization. Recognition activities, for instance-whether with donors, volunteers, or partner organizations-reward those who support the organization and encourage others to do the same. Volunteers who recognize themselves in photos can then reaffirm the benefits of the partnership, volunteer activity, or donation, while others can commend them for their dedication to the organization. Responding directly to comments and sharing information about operational activities in the offline world asserts accountability to their user base. Users considering volunteering or making a donation can see first-hand the degree to which their support will serve the organization's charitable cause. Finally, the use of the "Causes" Facebook app to support the crowdfunding of specific projects and programs is perhaps the ultimate way to tie donor relationships directly to organizational activities. Through "Causes," the organization can build a community around a cause in ways that simple policy information or meme-sharing cannot.

We also identified eight bridging strategies by identifying activities that appeared to be based on outreach and raising awareness of the cause. These include: 1) recruiting staff and volunteers; 2) using social bookmarks on the organization's website; 3 ) offering prize giveaways and trivia questions; 4) policy-related information sharing; 5) posting information on a weekly basis; 6) sharing memes, aphorisms, and inspirational quotations; 7) using Facebook's "Events" tool to remind followers of upcoming events; and 7) describing posts with hashtags. In general, these activities reflect an organization's willingness to use social media to attract new people to their web presence. Social bookmarks-weblinks on a website that encourage user to "like" or "follow" the organization-offer an easy way of showing support without having to donate money or advocate on behalf of the organization. Once bookmarked, the reader receives information from the organization on their chosen social media site and can choose whether to read it carefully, filter it, or ignore it. Prize giveaways and trivia contests offer a transactional incentive for followers to remain on the site, which has been shown to increase donors' willingness to encourage their own networks to donate (Castillo et al., 2014). As will be discussed later, these activities do not necessarily increase on-site engagement; however, they do demonstrate an organization's commitment to reaching out the community. 


\section{Deschamps \& McNutt (2014)}

Information sharing is a common bridging strategy. As outlined earlier, the regular posting of information is essential for consistent engagement of the public. In our criteria, we consider once a week to be a satisfactory benchmark for continuous information sharing. Sharing memes is another common way for organizations to ensure a steady stream of content on their organizational accounts. The term meme, coined by Richard Dawkins (2006), refers to any nongenetic apparatus (such as an idea) that replicates itself in some way, creating or defining cultural symbols in large groups of people. For Internet users, memes are pictures, sayings, videos, aphorisms, famous quotations, or novel ideas that are shared frequently over the Internet. For not-for-profit organizations in areas like disaster relief, education, and the environment, memes may be familiar quotations or aphorisms that apply to the mission of the organization. Sharing policy information is somewhat similar to the sharing of memes, except the information shared implies that the organization has some level of expertise or understanding of the policy topic for which they are sharing the information. The purpose of such information is to better inform public debate on social, economic, and environmental issues. By sharing policy-related information, organizations can join a number of interest groups that have varying opinions about the shared information.

Attaching hashtags to information posts is a very efficient way of sharing information with people who otherwise are not already engaged with the organization. The hashtag, popularized by Twitter, is a way of attaching a subject to a tweet or post by including the subject's name with an octothorpe, or hash sign (\#), in front of the word. For example, to indicate a post or tweet is about Canadian politics, one might add the hashtag \#cdnpoli. By placing a hashtag on a post, the profile enables users who click it to view all tweets that have the same hashtag. Facebook added this functionality in the summer of 2013. This process is a very efficient way for a user to examine what collective users think of a specific topic. By including a hashtag on a post, an organization can attract users who have searched for similar topics.

General performance criteria for social media are difficult to produce because of the varied nature of organizational goals, the varied size and structure of organizations, and differences in geographic focus and frequency of use. For our purposes, we chose four benchmark measures: 1) 1,000 likes on Facebook; 2) 1,000 followers on Twitter; 3) whether users have made three comments in the past three months; and 4) whether the organization was mentioned more than three times on Twitter in the past three months. Organizations that achieve all four of these benchmarks demonstrate some level of user engagement through their social media presence. Organizations that stand below the benchmarks on these criteria usually do so because they have chosen to neglect some aspect of their social media activity (e.g., choosing to feed Facebook statuses to a Twitter account instead of providing original content). In some cases, however, organizations achieved benchmarks despite their choice to neglect specific aspects of their social media presence. The Mennonite Disaster Service, for instance, received a large number of mentions on Twitter because of their support for people affected by the series of tornadoes in Moore and other areas of Oklahoma in 2013. The varied ways in which organizations achieve or fail to achieve these performance objectives suggests that offline activities affect online activities, and vice versa.

Three additional criteria examined the extent of social media use beyond Twitter and Facebook. All 45 organizations had a Facebook presence, and only two did not have a presence on either Twitter or Facebook, so we excluded participation in these networks in our criteria. However, we did examine whether the organizations had an integrated social media strategy. Thus, we also considered whether the nonprofits in our 


\section{Deschamps \& McNutt (2014)}

sample have a presence on YouTube and/or Linkedln, and we included a category for other social network sites. Examples of sites in the "other" category included Stumbleupon, Pinterest, Flickr, and Google+. However, we did not examine the additional use of these sites for the purposes of this study, electing instead to focus on the organizations' Twitter and Facebook presences.

Given the nature of organizations concerned with disaster relief, education, and environment, and the respective social media behaviours of these organizations, we believe it is useful to consider the use of "weak" versus "strong" social ties to evaluate the effectiveness of social media activities, based on tie strength strategies described by Granovetter (1973; 1983), Burt (1992), and Haythornathwaite (2002). It must be stated outright that taking an interpretive approach to social networks in this way poses a risk due to the possibility of multiple complex factors that may be at play. Nonetheless, this method offers an initial look at the "strong" and "weak" tie mechanisms that can help organizations achieve better results from their social media activities.

\section{THE STRENGTH OF TIES}

The wide-scale adoption of social media by not-for-profit organizations in Canada is evident in our sample (see Table 1). Almost every organization had a Facebook account, and an equally high proportion used Twitter and/or other social networking sites to optimize their online presence. Between 70 and 90 percent of organizations in all three categories of the sample place social bookmarks on their website to allow users to connect via social media. Over half of each sample posted content on their social media site more than once per week, using a mixture of photo-sharing, status sharing, and event reminders on their social networking accounts. YouTube, Linkedln, and other social networking sites appeared in another third of the sample as well. Approximately half of the organizations had more than 1,000 likes on Facebook (another 12 percent had more than 800 likes), and about a third had more than 1,000 followers on Twitter. While a few of the organizations had neglected their social media presence, the organizations in the sample overwhelmingly have made some effort to engage the public online.

\section{Disaster Relief}

Disaster relief organizations tended to adopt strong-tie strategies to attract the attention of users. These organizations spent more time recognizing volunteers, highlighting their daily activities and responding to questions, while their users reciprocated by making comments on their Facebook page. Most of the disaster relief organizations had more than 1,000 likes on Facebook, but fewer were engaged on Twitter, where social connection tends to be less cohesive. Many of the organizations used the "Causes" app. These bonding strategies were also implicit in other areas of the disaster relief organizations' social media use. Canadian Aid for Chernobyl, the Islamic Relief Fund, SolidARQu, the Canadian Central American Relief Fund, and the Bosnian-Canadian Relief Fund are examples of disaster relief organizations that used linguistic and national ties to attract users to their social media site. While strong ties provide the benefits of loyal membership who may be easier to engage, strategies that use strong ties must still rely on its user base to attract new people to the site. To use the example of a religious organization, members of the same religion are likely to be loyal to the cause because it promotes their own values, but attracting donors outside the religious group may require some other means besides promoting the values of the organization. 
Deschamps \& McNutt (2014)

\title{
Table 1: Social media optimization for third sector organizations
}

\section{Bonding Strategies}

Bridging Strategies

Extent of Use

Performance

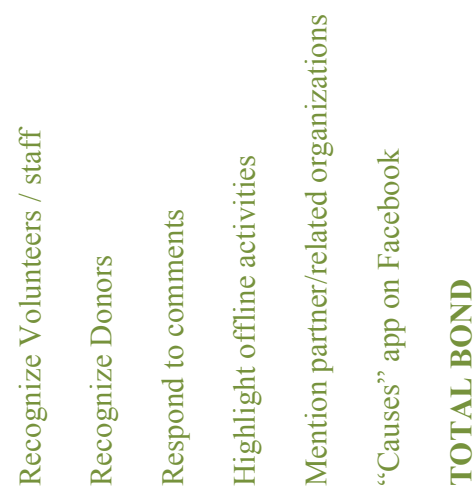

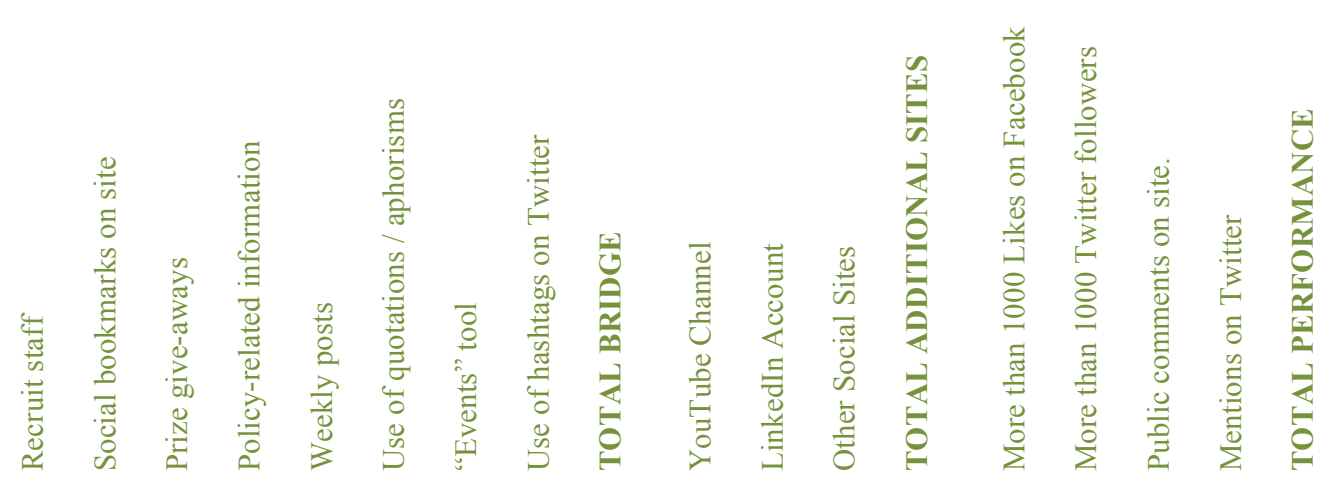

\section{$\begin{array}{llll}6 & 3 & 4 & 9\end{array}$}

1
1

볼

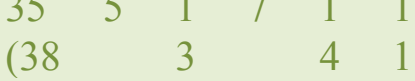

.9

\%)

\begin{abstract}
$\begin{array}{lllll}7 & 9 & 8 & 74 & 6\end{array}$
\end{abstract}
16

1.

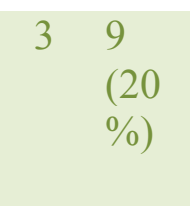

\section{9}

$\begin{array}{ll}1 & 38 \\ 1 & (63 \\ & .3 \\ & \%)\end{array}$

$7 \%$ 
Although organizations concerned with topical interests rather than social causes are better equipped to use weak-tie strategies, traditional or strong-tie-oriented organizations can apply weak-tie strategies as well. One strategy used by the Islamic Relief Society was to use a popular Canadian hockey star, Nazem Kadri, as a connector between the Islamic community and the community of hockey enthusiasts. Inspirational quotations can also be used as a means to show the universality of a cause beyond its traditional religious or national values.

\section{Educational Organizations}

In our sample, organizations that tend to shun reciprocal relationships excelled in engaging their public through information ties. Many educational organizations, for instance, attracted users by sharing policy-related information, or by applying hashtags to their posts. They were also more likely to share information using YouTube. Education institutions typically share information as a matter of course, so continuing to share information on the Internet is a natural extension of their operations. Take for example, the Writers' Trust of Canada. The Writers' Trust of Canada is an organization whose mission is to raise funds "to encourage a flourishing writer's community in this country [Canada]" (Writers' Trust of Canada, n.d.). Their activities include sharing information about events and programs of interest to writers across Canada and providing content that users can share on their own profiles, whether through the "share" mechanism, by "liking" it, or by retweeting on Twitter. Like the Islamic Relief Society, the Writers' Trust uses its celebrity backing (the organization was founded in part by popular Canadian novelist Margaret Atwood) to increase interest in the organization. On the other hand, despite multiple posts every week, the Writers' Trust Facebook account featured very few comments to suggest user engagement beyond a topical interest in books and writing. While the Writers' Trust's lack of engagement through comments could be seen as contrary to a "flourishing writer's community," this would be taking the concept of "strong" versus "weak" strategies too far. Writers' Trust may be developing very strong off-line community ties among their members, but their social media strategy is to leverage their abundance of useful and entertaining content, instead of those community ties.

Responding directly to users was more effective for disaster relief organizations than it was for education groups. All of the disaster relief organizations that replied directly to users had more than 1,000 likes on Facebook. Conversely, only one of the two education organizations that responded directly to users had more than 1,000 likes on Facebook. More research is necessary to better understand the relationship between engagement on Facebook and attracting an audience; however, it does appear that human services organizations are better equipped than other organizations to attract an engaged user base by communicating directly with their online users. 


\section{Deschamps \& McNutt (2014)}

\section{Environmental organizations}

The environmental organizations in our sample adopted both strong- and weak-tie strategies, but were less likely to extend their presence beyond Facebook and Twitter. This is partially explained by the goals of the organizations. Most environmental organizations recognize that raising awareness of environmental issues requires, on the one hand, engaged communities of scientists, activists, and technologists, and on the other, widespread sharing of policy-related information to the broader public, in order to encourage change in government, industry, and consumer behaviour. Unsurprisingly, all but one of the environmental organizations used their social media presence to share policy-related information. Their activities to encourage comments on the site, however, challenge our use of user comments as a measure of strong-tie strategies. In many cases, comments and commentary were more related to encouraging public debate on issues such as biodiversity, food security, and climate change. For example, Food Secure Canada has managed to encourage considerable debate on their Facebook page even though the only strong-tie strategy they applied was to mention partner organizations. There are a number of possible explanations for this result. First, food security involves an already tight circle of agriculture and food advocates that may have already-established virtual communities that gather on the Food Secure Canada Facebook page. Second, the analysis of these pages was conducted at a time of increased policy attention on genetically modified foods. Finally, strong-tie activities may be occurring where we cannot observe them-for instance, perhaps Facebook and other information is also being shared through email, community meetings, and so forth.

\section{COMBINING WEAK AND STRONG STRATEGIES}

Whether strongly or weakly connected, nonprofits that apply a user-centred approach to their social media accounts tend to engage more users. While recording organizational activity, calling for volunteers, and requesting donations is common practice for nonprofits interested in being accountable to their respective boards and funders, our evidence suggests that online users are less likely to be interested in this kind of information. The user-centred approach focuses on the interests and values of the user base instead. For instance, rather than showing pictures of operational activities, an organization could present videos, pictures, or quotations that can spark a conversation aligned with the organization's values. Our data show that a greater diversity of activities and content will attract a larger user base. The use of Facebook by celebrity George Takei is one example. Intertwined with posts promoting Takei's acting activities and LGBT rights, Takei shares clever puns and jokes about geek culture (known for playing Lieutenant Sulu on the original Star Trek, Takei has a fanbase that is interested in geek/science fiction subculture).

In our sample, Nature Conservancy Canada is worthy of particular mention because of their ability to apply both weak- and strong-tie strategies to engage their audience. On the one hand, their posts showcase staff and volunteers working in the field, to assure donors and supporters that they are actively putting resources to good use. On the other hand, they create a theme for these posts using the hashtag \#fromthefield, which helps users easily share this information. Because their field posts are tagged, not only can a user know quickly that the post is a portrayal of the organization at work, they can also click on the tag to see examples of the work being 


\section{Deschamps \& McNutt (2014)}

done by the organization. They use other tags such as \#spotthespecies and \#NCCLive to quiz their audience on biodiversity and to let them know when they are actively streaming content to Facebook. Their use of these tags encourages weak-tie users to more actively engage with their content, while making it easy for strong-tie users to expand their content beyond the parochial. Thanks to these efforts, Nature Conservancy of Canada has over 26,000 likes on Facebook, over 9,900 followers on Twitter, multiple comments on many of their daily posts, and a large number of supporters on Twitter promoting the organization's funding drives, programs, and other activities.

Bridging strategies can also improve the impact of advertising. After we chose to "like" the Islamic Relief Fund as part of this research, the organization appeared in ads on YouTube, in Google searches, and in other channels. The video-based ad used visual images depicting young children in wartime situations and was part of an annual appeal that occurs during Ramadan. One of the key benefits of bridging techniques on social media is that once engaged, further ads and promotions become more visible to the user, permitting the availability of more visual appeals for donations, volunteer opportunities, or other opportunities to bond with online users.

One activity that does not appear to benefit social media activities is the use of web-based software to feed posts from one social media account to another. Though providing the same content to multiple sites is less effort, this approach gives users the impression that the organization's attention is elsewhere. This outcome suggests that social media is not a user group in and of itself. Different users use different social media for different reasons, and automatic feeds tend to take organizational statements out of their original context. When organizations apply this strategy, the difference between two different social networking sites is thrown into relief.

\section{DISCUSSION AND RECOMMENDATIONS}

The findings of our study suggest that social media optimization requires strategic planning on the part of nonprofits, with the appropriateness of different strategies largely dependent on an organization's missions and goals. The social media practices of the educational, environmental and disaster relief organizations in our sample varied dramatically. While disaster relief organizations tended to adopt strong-tie strategies (bonding), educational organization used weak-tie strategies (bridging), and environmental organizations demonstrated a commitment to both. The current literature on smart practices in nonprofits' applications of social media suggests that all these tools can engage donors, share information, recruit volunteers, engage the public, target specific demographics, demonstrate accountability, and enhance linkability. Our study's findings support the argument that all of these practices are key to social media optimization. In addition to the existing list of smart practices, we would add bridging and bonding as key considerations in a strategic social media program.

To achieve an effective strong-tie strategy, organizations might begin with staff and volunteers. A simple strategy is to set an expectation that all staff include the organizations' Facebook and Twitter accounts on their email signatures. Requesting that volunteers and donors promote the cause through their own social media sites is another simple but effective strategy to leverage an organization's strong ties online. Providing some 


\section{Deschamps \& McNutt (2014)}

staff training in what social media is, how it is used, and what risks are associated with its use can further encourage staff to engage on social media sites; in so doing, they may promote organizational events, affirm the social benefits of programs, and demonstrate enthusiasm for the organizations vision and mission. However, capacity issues can be a risk factor in social media use, as monitoring and maintaining social media activity can be time consuming and difficult, particularly if volunteers are asked to spread the word via their own personal channels.

While adopting a weak-tie strategy attracts viewers to the messaging site, it is unclear whether this attraction supports the objectives of the participating organizations. Other than the David Suzuki Foundation, none of the organizations we examined have what the online world would consider celebrity status, and the mere existence of Facebook friends does not mean that a large amount of funding will come from online sources. It may be that users expect the nonprofits they support to have some kind of social media presence, regardless of how effective it is strategically.

This study assumes that a social media strategy is a desired component of a charitable organization's mission. In reality, however, social media may not make sense for all organizations. While a social media presence is fairly easy to set up, it is not always easy to maintain. Depending on the strategic mission of the organization, social media engagement can lead to "mission creep," as attracting an online public distracts the organization from its original purpose. Social media can also be a liability in some cases, as stakeholders and government can monitor social media activity more closely than they can day-to-day activity. In particular, nonprofits must take care not to share too much advocacy information on their channels, as this can threaten their status as a registered Canadian charity.

While many nonprofits use social media effectively, a great deal of research remains to be done around social media optimization. The primary limitation of this research is that it favours the interpretation of social media content, at the expense of examining more complex, and therefore difficult to measure, variables such as organization size, existing network arrangements, provincial and municipal institutional arrangements, and so on. Further study, perhaps using multivariate analysis of social networks, would be useful for developing more complete models of social media optimization. In addition, research on the experimental use of social entrepreneurial activities and crowdfunding will be important considerations in long-term strategic social media planning. Other potential challenges associated with nonprofits' adoption of social media will include accessibility, privacy, and e-inclusion, all of which require further study. There is also room for more studies of how nonprofits are using digital tools for different purposes, along the lines of Waters, Burnett, Lamm, and Lucas' (2009) study on stakeholder engagement. Much recent research suggests that what the market is to the private sector, and what hierarchy is to the public sector, networking is to the third sector.

\section{ACKNOWLEDGEMENTS}

The authors would like to acknowledge the anonymous reviewers who helped to improve the article overall. 


\section{Deschamps \& McNutt (2014)}

\section{REFERENCES}

Amichai-Hamburger, Y. (2008). Potential and promise of online volunteering. Computers in Human Behavior, 24, 544-562.

Banias, P., \& Malita, L. (2011). Can we use sport, Web 2.0 and social \& informal learning to develop \& enhance social competences? Procedia - Social and Behavioral Sciences, 15, 628-632.

Berman, S.J., Abraham, S., Battino, B., Shipnuck, L., \& Neus, A. (2007). New business models for the new media world. Strategy \& Leadership, 35, 23-30.

Briones, R.L., Kuch, B., Fisher, B., \& Liu, J.Y. (2011). Keeping up with the digital age: How the American Red Cross used social media to build relationships. Public Relations Review, 37, 37-43.

Burt, R.S. (1992). Structural holes: The structure of competition. Cambridge, MA: Harvard University Press.

Burt, R.S. (2004). Structural holes and good ideas. American Journal of Sociology 110 (2), 349-399.

Castillo, M., Petrie, R., \& Wardell, C. (2014). Fundraising through online social networks: A field experiment on peer-to-peer solicitation. Journal of Public Economics, 114, 29-75.

Chew, C., \& Osborne, S.P. (2009). Identifying the factors that influence positioning strategy in U.K. charitable organizations that provide public services: Towards an integrating model. Nonprofit and Voluntary Sector Quarterly, 38, 29-50.

Curtis, L., Edwards, C., Fraser, K.L, Gudelsky, S., Holmquist, J., Thornton, K., \& Sweetser, K.D. (2010). Adoption of social media for public relations by nonprofit organizations. Public Relations Review, 36, 90-92.

Dawkins, R. (2006). The selfish gene: With a new introduction by the author. UK: Oxford University Press. (Originally published in 1976)

Dhebar, B.B., \& Stokes, B. (2008). A nonprofit manager's guide to online volunteering. Nonprofit Management and Leadership, 18, 497-506.

Fischer, F. (2003). Reframing public policy: Discursive politics and deliberative practices. UK: Oxford University Press.

Frick, T. (2010). Return on engagement: Content, strategy, and design techniques for digital marketing. New York, NY: Focal Press.

Gandía, J.L. (2011). Internet disclosure by nonprofit organizations: Empirical evidence of nongovernmental organizations for development in Spain. Nonprofit and Voluntary Sector Quarterly, 40, 57-78.

Gordon, T. P., Khumawala, S.B., Kraut, M., \& Neely, G.D. (2010). Five dimensions of effectiveness for nonprofit annual reports. Nonprofit Management \& Leadership, 21, 209-228.

Guo, C., \& Saxton, G. D. (2013). Tweeting social change: How social media are changing nonprofit advocacy. Nonprofit and Voluntary Sector Quarterly. Advance online publication. DOI: 10.1177/0899764012471585

Granovetter, M.S. (1973). The strength of weak ties. American Journal of Sociology, 1360-1380.

Granovetter, M.S. (1983). The strength of weak ties: A network theory revisited. Sociological Theory, 1(1), 201-233.

Granovetter, M.S. (2005). The impact of social structure on economic outcomes. Journal of Economic Perspectives, 19, 33-50.

Grant, S. (2009). Silos of helplessness: A cautionary tale about introducing social media (Web 2.0) applications in the community sector. Third Sector Review, 15, 89-104. 


\section{Deschamps \& McNutt (2014)}

Greenberg, J., \& MacAulay, M. (2009). NPO 2.0? Exploring the web presence of environmental nonprofit organizations in Canada. Global Media Journal-Canadian Edition, 2, 63-88.

Hackler, D., \& Saxton, G.D. (2007). The strategic use of information technology by nonprofit organizations: Increasing capacity and untapped potential. Public Administration Review, 67, 474-487.

Haythornathwaite, C. (2002). Strong, weak and latent ties and the impact of new media. The Information Society, 18, 385-401.

Kanter, B., \& Fine, A. (2010). The networked nonprofit: Connecting with social media to drive change. San Francisco: John Wiley \& Sons.

Kaplan, A. M., \& Haenlein, M. (2009). The fairyland of Second Life: Virtual social worlds and how to use them. Business Horizons, 52, 563-572.

Kenix, L.J. (2008). The Internet as a tool for democracy? A survey of non-profit Internet decision-makers and web users. First Monday, 13. URL: http://firstmonday.org/ojs/index.php/fm/article/view/2124 [August 21, 2013.]

Kirk, G., \& Nolan, S.B. (2010). Nonprofit mission statement focus and financial performance. Nonprofit Management and Leadership, 20, 473-490.

Lai, L.S.L., \& Turban, E. (2008). Groups formation and operations in the Web 2.0 environment and social networks. Group Decision and Negotiation, 17, 387-402.

Lovejoy, K., \& Saxton, G.D. (2012). Information, community and action: How nonprofit organizations use social media. Journal of Computer-Mediated Communication, 17, 337-353.

Lovett, J. (2011). Social media metrics secrets. Indiana: Wiley Press.

Mansfield, S.J., Morrison, S.G., Stephens, H.O., Bonning, M.A., Wang, S.H., Withers, A.H., \& Perry, A.W. (2011). Social media and the medical profession. Medical Journal of Australia, 194(12), 642-644.

McNutt, K. (2012). Climate change subsystem structure and change: Network mapping, density and centrality. Canadian Political Science Review, 6, 15-50.

Mehta, R. (2011). Flash activism: How a Bollywood film catalyzed civic justice toward a murder trial. Transformative Works and Cultures, No. 10. DOI: 10.3983/twc.2012.0345

Miller, B. (2009). Community fundraising 2.0-the future of fundraising in a networked society? International Journal of Nonprofit and Voluntary Sector Marketing, 14, 365-370.

Nah, S., \& Saxton, G.D. (2013). Modeling the adoption and use of social media by nonprofit organizations. New Media \& Society, 15(2), 294-313.

Neff, D.J., \& Moss, R.C. (2011). The future of nonprofits: Innovate and thrive in the digital age. Danvers, MA: Wiley.

Purdy, C.H. (2011). Using the Internet and social media to promote condom use in Turkey. Reproductive Health Matters, 19, 157-165.

Reynolds, B. (2010). Building trust through social media. CDC's experience during the H1N1 influenza response. Marketing Health Services, 30, 18-21.

Russo, A., Watkins, J., Kelly, L., \& Chan, S. (2008). Participatory communication with social media. Curator: The Museum Journal, 51, 21-31.

Sabatier, P.A. (1991). Toward better theories of the policy process. PS: Political Science \& Politics, 24, 147-156.

Saxton, G.D., \& Guo, C. (2011). Accountability online: Understanding the web-based accountability practices of nonprofit organizations. Nonprofit and Voluntary Sector Quarterly, 40, 270-295. 
Scott, S.V., \& Orlikowski, W.J. (2012). Reconfiguring relations of accountability: Materialization of social media in the travel sector. Accounting, Organizations and Society, 37(1), 26-40.

Shirky, C. (2011). The political power of social media. Foreign Affairs, 90, $28-41$.

Vance, K., Howe, W., \& Dellavalle, R.P. (2009). Social internet sites as a source of public health information. Dermatologic Clinics, 27(2), 133-136.

Waters, R.D. (2009). The use of social media by nonprofit organizations: An examination from the diffusion of innovations perspective. In S. Dasgupta (Ed.), Social computing: Concepts, methodologies, tools, and applications (pp. 1420-1432). Pennsylvania: IGI Global.

Waters, R.D. (2007). Nonprofit organizations' use of the Internet: A content analysis of communication trends on the Internet sites of philanthropy. Nonprofit Management and Leadership, 18, 59-76.

Waters, R.D., Burnett, E., Lamm, A., \& Lucas, J. (2009). Engaging stakeholders through social networking: How nonprofit organizations are using Facebook. Public Relations Review, 35, 102-106.

Waters, R. D., \& Jamal, J.Y. (2011). Tweet, tweet, tweet: A content analysis of nonprofit organizations' Twitter updates. Public Relations Review, 37, 321-324.

Waters, R.D. \& Jones, P.M. (2011). Using video to build an organization's identity and brand: A content analysis of nonprofit organizations' YouTube videos. Journal of Nonprofit \& Public Sector Marketing, 23, 248-268.

Watling, S. (2011). Digital exclusion: Coming out from behind closed doors. Disability \& Society, 26(4), 491-495.

Writers' Trust of Canada. (2013). About Us. The Writers' Trust of Canada. [Website]. URL: http://www.writerstrust.com/About.aspx [August 21, 2013.]

\section{ABOUT THE AUTHORS / LES AUTEURS}

Ryan Deschamps is a PhD candidate at the Johnson-Shoyama Graduate School of Public Policy. Email: ryan.deschamps@gmail.com .

Kathleen McNutt is Director, University of Regina campus, Johnson-Shoyama Graduate School of Public Policy, and Associate Member, Department of Political Science, University of Regina. Email: kathy.mcnutt@uregina.ca . 